\author{
Educational Research for Social Change (ERSC) \\ Volume: 7 No. 1, April 2018 \\ pp. 46-60 \\ ersc.nmmu.ac.za
}

ISSN: 2221-4070

\title{
A Social Justice Approach to Providing Academic Writing Support
}

\author{
Avasha Rambiritch \\ University of Pretoria \\ avasha.rambiritch@up.ac.za
}

\begin{abstract}
The value of the support provided in a writing centre is well documented today in international literature. However, an area largely untouched has been how to implement social justice principles in the context of a writing centre. In many of the articles on writing centre support, mention is made of the fact that writing centre work is social justice work without fully defining the nature of the actual principles of this social justice. It is hoped that this paper makes a contribution in this regard. The paper begins by looking in detail at the concept of social justice, before identifying particular principles of social justice drawn from critical pedagogy that can be applied to the support provided in a writing centre. The discussion also integrates qualitative evidence gathered from a questionnaire administered to five writing consultants employed in a writing centre, as well as quantitative data generated by the online booking system used in the writing centre. An analysis of the data shows that these social justice principles are energised during the dialogue that takes place during consultations. Justification for this study stems from the need to see these issues, not as abstract concepts or as discussion tools for the experts who make important decisions but, as important in determining why and how they can be applied in practice in the writing centre.
\end{abstract}

Keywords: social justice, academic writing, writing centre, student empowerment, student-centred pedagogy

Copyright: (C) 2018 Avasha Rambiritch

This is an open access article distributed under the terms of the Creative Commons Attribution Non-Commercial License, which permits unrestricted non-commercial use, distribution, and reproduction in any medium, provided the original author and source are credited.

Please reference as: Rambiritch, A. (2018). A Social Justice Approach to Providing Academic Writing Support. Educational Research for Social Change, 7(1), 46-60. http://dx.doi.org/10.17159/22214070/2018/v7i1a4

\section{Introduction}

South Africa's somewhat chequered history and its inability, even some 20 years after democracy, to provide quality education to the majority of its school-going population required a number of alternative interventions to be implemented at, specifically, higher education level to at least attempt to level the playing field for its students. The interventions put in place to widen participation have been well-documented in the research and will be touched on very briefly later in this paper. But together with these implemented interventions, other cries for a socially just education system echo 
around us; attempts to redress the inequalities of the past have been accompanied by calls for the widening of participation, access, free education, social justice, and curriculum transformation. My concern in this paper, however, especially in light of the nature of my work, is limited to social justice. While the call for free education and curriculum transformation are equally important, these issues can be more broadly considered policy issues-over which the lecturer has little to no control. This paper will attempt to show how and why social justice issues do not need to be abstract concepts or discussion tools for the experts who make policy decisions but, equally importantly, can be applied in practice in the academic literacy classroom. What would be valuable would be for those of us on the ground to be able to practically apply these principles to our teaching and the support we render in higher education. Issues related to providing a socially just education to our students cannot remain abstract concepts in policy documents. A truly socially just education system happens practically in the classroom, in our curriculum, in our assessments, and in the everyday support we provide to our students. So the question that signals the real beginning of this text is, simply, "What is social justice and how can social justice principles be applied to the work of the academic literacy teacher-lecturer?" Throughout the course of this journey, and in attempting to answer these questions, I hope to arrive at a clearer understanding of how these social justice principles can be applied by looking briefly at the support offered in the context of a newly established writing centre.

\section{Understanding Social Justice}

On delving into the literature on social justice, it becomes clear very early on that its definition is somewhat elusive. This is not to say that there is not sufficient literature available to help understand the term, but that the sheer abundance of literature and the vast usage of the term across a number of disciplines make a single definition difficult to grasp. This is a view shared by a number of contributors. For Sleeter (2014), "the term 'social justice' is so widely used that I have become concerned it may lose its meaning," while Brennan and Naidoo (2008, p. ?) stated that "concepts such as equity and social justice ... are frequently used without clear and agreed definition." For Rezvi (in Ayers, Quinn, \& Stovall, 2009), "any comparative and international analysis of social justice and education indicates the impossibility of a universal definition" (p. 91) and,

The trouble with "social justice" begins with the very meaning of the term. Hayek points out that whole books and treatises have been written about social justice without ever offering a definition of it. It is allowed to float in the air as if everyone will recognise an instance of it when it appears. This vagueness seems indispensable. The minute one begins to define social justice, one runs into embarrassing intellectual difficulties. (Novak, 2000, p. 11)

One cannot ignore or dismiss Novaks's blatantly honest admission of "running into embarrassing intellectual difficulties" (2000, p. 11) in this regard. Nelson and Creagh (2013, p. 102) referred back to ancient Greek and Roman times when the notions of justice and equality were used to organise political and social life. These same notions of justice were taken up by philosophers Rousseau (1754) and Kant (1784) with an emphasis on justice and equality (as cited by Lane, 2011 in Nelson \& Creagh, 2013), by Rawls in his A Theory of Justice (1971), which foregrounds the idea of justice as fairness through the principles of liberty and equality, and by Young (1990) who, in critiquing Rawls' definition of justice as "being too restrictive" (as cited in Lotter, 1999, p. 90), proposed to "widen the scope of the concept of justice to include topics like decision-making, culture, and the division of labour" (Lotter, 1999, p. 90). Importantly, Young challenged the idea of distributive justice, defined by Rawls (1971, p. 7) as concerning "the way in which the major social institutions ... distribute fundamental rights and duties and determine the distribution of advantages from social co-operation." According to Lotter (1999, p. 90), Young's main complaint "about the contemporary philosophical discourse about justice is that the meaning of the concept of justice is restricted to matters concerning distributive justice." 
Young 1990 further stated that the idea of distributive justice suggests a "focus on persons as consumers and possessors" and that "visualising problems of justice as goods that must be distributed obscures the fact that many actions of people result from processes and relations, rather than being static things" (as quoted in Lotter, 1999, p. 16). What Young suggested, instead, is a broader scope of justice that includes all aspects of public life-political and economic institutions, family institutions, and civil society (as cited in Lotter, 1999). Lotter referred to Young's idea of justice as enablement, that is,

the extent to which institutional conditions in a society enable or constrain people to learn and use skills, to play and communicate with others, participate in running institutions, share in determining their own lives, and express their feelings, experiences, and perspectives. (Young, 1990, p. 37, as quoted in Lotter, 1999, p. 95)

As we seek to understand the idea of social justice, we see the way in which the term, originally used by the ancient Greeks and Romans as a political philosophy to organise society, today begs the question: "How can we contribute to the creation of a more equitable, respectful, and just society for everyone?" (Zaijda et al., 2006, quoted in Brennan \& Naidoo, 2008, p. 287). Thinking around the idea of social justice, then, is automatically associated with ideas of equality, equity, and justice.

How, then, does the understanding of the idea of social justice exist in the context of education, specifically higher education? At first glance when considering the idea of social justice in education, especially in South Africa, the idea of social justice revolves around Young's (in Lotter, 1999) idea of distributive justice-focus seems to be around ideas of widening participation, the idea of equal distribution. De Kadt (2009) highlighted areas in the South African education system that desperately need reform: the poor quality of the majority of public education; inequality in terms of quality (of education), resources, and opportunities; and educational segregation along socioeconomic lines. She stated that the only way of creating an educational system that is just, and that supports social justice, is to address these issues. De Kadt (2009) raised important concerns. These same concerns were raised by McInerney (2004) who, while writing within the Australian context, pointed to issues of concern there as well: socioeconomic disadvantage, racism, and cultural oppression. However, as pointed out early in this paper, the aim here is not to limit our understanding of a socially just higher education to referring to issues of widening participation and equality of access. Some measure of progress has been made, and continues to be made in this regard. Ramrathan (2016) pointed out that in 2011 audited statistics indicated that approximately 938,000 students were enrolled in higher education across public universities, growing from 495,000 in 1994. Lewin and Mawoyo (2014, p. 23) indicated that the enrolment of African students rose from 43\% of total enrolment in 1994 to $67 \%$ in 2010, and from $55 \%$ in 1994 to $81 \%$ in 2011. David (2010, p. 15), in defining the idea of widening participation, stated that it is taken to mean "extending and enhancing access to and experience of higher education, and achievement within higher education of people from so-called under-represented and diverse social backgrounds, families, groups and communities." In South African higher education institutions, in addition to widening participation, a number of intervention programmes were implemented, and continue to be implemented, to support students who may be inadequately prepared to cope with their studies. The trend has been to set up specific programmes to assist these students. Different institutions have, however, taken different routes. Some have set up academic support programmes, departments, and units, while others have offered degrees and diplomas on an extended programme system, where the programme is extended by a year to ensure that the relevant academic support is provided. The academic support tends to concentrate on language proficiency, computer literacy, and mathematics literacy. Institutions in South Africa either set up discipline-specific development programmes, dedicated to increasing access for previously disadvantaged students in the natural sciences, or they target critically important areas of ability known to cause concern (Unit for Academic 
Literacy, 2007). Today, a whole range of solutions, stretching from the general to the specific, is often combined, maximising their respective strengths (Unit for Academic Literacy, 2007).

\section{Social Justice, Critical Pedagogy, and Higher Education}

While these strategies attempt to implement a socially just education, to many of us on the ground the question still remains: "How do we make this educationally relevant every day in our teaching and the support we provide?" Equality and access do not a socially just education system make. This view is supported by a number of experts who, in sum, believe that Rawls's idea of distributive justice, simply applied to education, does not create social justice in education. Rizvi (quoted in Ayers et al., 2009, p. 93) stated that,

the traditional ways of thinking about social justice in education assumed a strong role for the state in bringing about greater equality of access ... but . . . this logic is inadequate in fully accounting for non-material resources such as respect, recognition, rights, opportunities, and power.

Patton, Shahjahan and Osei-Kofi $(2010$, p. 268), in a similar vein, stated:

In the higher education context, we can fall into the trap of equating social justice with distributive justice by exclusively focusing on distribution questions-numerical representation of minoritisized bodies among faculty, students and administrators in universities, college access, voice in the classroom, curricula, and so on-and ignore the social structures, processes, and institutional contexts that produce these distributions in the first place.

For Boyles, Carusi, and Attick (in Ayers et al., 2009), conceptualising social justice as an ideal that exists within a distributive paradigm can mean that scholars and education leaders, with ideologies that remain contrary to social justice, can claim to promote social justice by providing students equal access to education. Importantly, they state that a non-distributive notion of justice in education is an unattainable goal within an education system that promotes justice as existing when students are given equal access to education (Ayers et al., 2009, p. 40). So the underlying questions remain: What does it mean to adopt a social justice approach in the work that we do in higher education? To extend the idea of access and equality from the perspective of the policy and the institution to that of the teacher/lecturer/facilitator of learning? To move beyond equity and social justice being seen as mere buzzwords and instead becoming part of the lived practise in the classroom (Hackman, 2005, p. 103)? And to (re)envision the possibilities of higher education research and praxis through a social justice lens (Patton et al., 2010, p. 268)?

This need to revisit our understanding of social justice was reiterated by Fraser $(2005$, p. 71$)$ who stated that there is a need to change the way we argue about social justice. Her earlier argument that social justice should include consideration of socioeconomic redistribution (distributive justice) and legal or cultural recognition-aspects that she referred to as the what of justice (i.e., what is owed)-is extended to include the political dimension (i.e., the how of social justice). The question this presents is simple: How do we do social justice? Fraser's (2005) multidimensional frame for social justice extended the basic definition of social justice to encompass parity of participation, that is, justice that requires social arrangements that permit all to participate as peers in social life. She stated, "Overcoming injustice means dismantling institutionalised obstacles that prevent some people from participating on a par with others, as full partners in social interaction" $(2005$, p. 73$)$. This would be the ideal-an understanding, acceptance, and application of a social justice system that sees and accepts all participants as equals. Are there, perhaps, principles of social justice that can be applied in the 
teaching and learning that takes place in the higher education classroom that contributes, or creates opportunities for all participants to participate as equals?

Over 40 years ago, Freire (1970) recommended pedagogical methods that recognised the experience and dignity of students and their culture. He argued against what he called "the banking concept of education" (1970, p. 53) where education becomes the act of depositing, in which the students are depositories and the teacher the depositor. He stated that,

in the banking concept of education, knowledge is a gift bestowed by those who consider themselves knowledgeable upon those who they consider to know nothing. Projecting an absolute onto others, a characteristic of the ideology of oppression, negates education and knowledge as a process of inquiry. (Freire, 1970, p. 53)

According to Freire (1970), social justice in education is allowing students to be inquirers, not containers; to present an education that encourages dialogue, problem solving and critical thinking. Freire's (1970) ideas have been instrumental in transforming the way educators think about and approach language teaching and learning. His, and other similar views (Giroux, 1997; Gor, 2005) have been the foundation on which critical pedagogy is based. The real value of critical pedagogy lies in its aim to provide an education that is transformative, empowering, and student-centred. Freire (1970) advocated for dialogue as a key component in the classroom. He said that "without dialogue there is no communication, and without communication there can be no real education" (1970, p. 74). For him, the banking concept of education resists dialogue while a problem-solving education regards dialogue as indispensable to the act of cognition, which unveils reality (Freire, 1970, p. 64). Clearly then, for critical pedagogists like Freire (1970), a truly just education system is one which, in the act of dialogue, encourages the asking and answering of questions through the process of critical thinking. This was confirmed by Aliakbari and Faraji $(2011$, p. 77) who stated that, through problem-posing education and questioning the problematic issues in learners' lives, students learn to think critically and develop a critical consciousness that helps them to improve their life conditions and take the necessary actions to build a more just and equitable society.

Thirty-five years later, thinking had not changed. Hackman (2005, p. 103) stated that social justice education encourages students to

take an active role in their own education and supports teachers in creating empowering, democratic, and critical educational environments; and that it includes student empowerment, the equitable distribution of resources, social responsibility, democracy, a student-centred focus, dialogue and an analysis of power.

Similar principles were highlighted by Dover (2013), who stated that teaching for social justice draws most heavily from five conceptual and pedagogical philosophies: democratic education, critical pedagogy, multicultural education, culturally responsive education, and social justice education. Within these five traditions aspects such as participatory pedagogy, problem solving, critical thinking, dialogue, inclusivity and holistic education are key.

The review above intended to present, albeit succinctly, thinking around the idea of social justice (and its relation to critical pedagogy). Importantly, the review may allow us to see how the broader aspect of social justice as doing the right thing, as equality, and as access can, perhaps, be narrowed to the context of higher education, and then narrowed even further to principles that can be applied to the setting of the higher education classroom. As indicated above, based on the ideas of Freire (1970), Hackman (2005), and Dover (2013), these principles include, though are not limited to, dialogue, 
problem solving, critical thinking, student empowerment, student-centred focus, holistic education, and analysis of power. How, then, can these principles be applied to teaching and learning in the context of a writing centre?

\section{Social Justice and Critical Pedagogy in the Context of a Writing Centre}

The value of the support provided in a writing centre, previously considered a largely North American creation, is well-documented today in international literature. From Olsen's (1984) contribution on the theory and administration of a writing centre to North's (1984) seminal article proclaiming the need to create better writers, not better writing, Harris's (1986) contributions on conversations, to Archer and Richards' (2011) contribution on writing centres here in South Africa, not much has been left undocumented about writing centre work. However, an area largely untouched has been how to implement social justice principles in the context of a writing centre. Many of the articles on writing centre support mention that writing centre work is social justice work. That the "writing centre aims to promote and facilitate access to higher education, within an ethos of social justice and national redress" (Archer, 2011, p. 355). And that "social justice and the democratisation of higher education have always been part of the mission of writing centres" (Trimbur, 2014, p. 67, quoted in Archer \& Parker, 2016, p. 44) without fully defining the nature of the actual principles of this social justice. It is hoped that this paper makes a contribution in this regard.

The need to answer this question stems from my own personal experience of being tasked with the responsibility of establishing the first writing centre, not just within the faculty, but within the institution as well. The writing centre was established with very little other than a venue, salaries, and the foresight of a director kind enough to fund the purchase of a computer. Now, some two and a half years later amidst the turbulence that often engulfs higher education, we are asking whether the work we do makes a real difference. The writing centre as a largely marginalised space, serving a largely marginalised student body is not new. And yet we knew from its inception that this was exactly what we wanted to move away from. We hoped that our mission echoed this ideal:

To provide writing support to undergraduate students in the Faculty of Humanities by creating a positive and professional environment in which students can engage in focused dialogue with consultants about their academic writing. (University of Pretoria, n.d.)

The one-on-one consultations are what set apart a writing centre from other support services offered by the university. The literature on peer tutoring and collaborative learning is rich with evidence of the success of these strategies (Longfellow, May, Burke, \& Marks-Maran, 2008; Rambiritch, 2016; Shrestha $\&$ Coffin, 2012). Tutor-assisted learning or peer-assisted learning can be understood as the learning process that sees a senior student, or a more experienced learner, support or guide a student who is less experienced, less expert, or less knowledgeable (see Bruffee, 1984; Fouche, 2007; Grant \& Hoeber, 1978; Maxwell, 1990). These and other studies highlight the value of tutor or peer-assisted learningthis is especially so in a country like South Africa where most tertiary institutions need measures in place to assist under- or poorly prepared students. Thus, the value of this individual support in a writing centre cannot be overemphasised. It is, however, essential to ensure that consultants and tutors who are a part of this dialogue understand clearly the significance of this conversation, as well as the subtle rules that underlie effective conversations in a writing centre. As part of the initial full-day training, and guided by Brooks (1991), Harris (1986), and Thompson and Mackiewicz (2014), consultants were introduced to strategies to be used during conversations with students. These included advice on the Socratic method of tutoring where consultants ask questions rather than give instructions: Rather than "You don't have a thesis," ask "Can you show me your thesis statement?" Socratic dialogues are active discussions between the consultant and the student to formulate and express his or her thoughts (Brooks, 1991). Related to this, Brook's (1991) idea of minimalist tutoring is discussed in detail. 
Minimalist tutoring requires students to solve their own problems under the supervision of a tutor who acts as a coach, a more experienced peer rather than an editor, and values small victories on the way to greater student skill and independence. Lastly, students are introduced to Pemberton's Law of Tutorics, which is similar to the previous two strategies in that it encourages the tutor or consultant to allow the student to take the lead in the dialogue. But what does this mean in practice?

The writing centre that is the focus of this study employs five writing centre consultants who are all postgraduate students. They are quite diverse in race, age, discipline of study, and language. As a group, they speak a combination of at least five different South African languages. Students using the writing centre can then choose to consult in English or a language both the consultant and the student are comfortable in (this is discussed further in the Findings and Discussions section below). Students are required to bring a draft of a text they are working on to the consultation. While the text is the focus of the discussion, the student maintains complete ownership of the text. The consultant does not write on the text or make changes to the text. This is one way of ensuring that the consultation remains a dialogue and not an editing session. Equally important, is the need for the student to see himself or herself as an equal partner in this process. Students who visit the writing centre arrive expecting to be told what to do. By drawing them into the discussion, asking them their thoughts on the topic they have to write about, and sometimes even venturing into discussions not directly related to the text, a student can begin to feel accepted, acknowledged, and respected. This can become the ideal platform to give the student a voice. The consultation then becomes about satisfying the needs of the student as opposed to focusing on what the tutor assumes the student needs. O' Neill and McMahon (2005), in discussing the concept of a student-centred pedagogy, stated that it is reflective of the democratic society that respects individual freedom and choice; already there is a shift in the dynamics of power the student is generally accustomed to. In the setting of the classroom or lecture hall, seeing the lecturer as the expert, and surrounded by other students, the student is often voiceless and powerless. In the context of the writing centre consultation, the student is an equal partner whose voice, views, and questions are an essential part of the dialogue. The next section of this paper will, therefore, look at how the social justice principles, identified above, are applied in a writing centre in order to create the safe space students need to find and use their voices.

\section{Methodology}

The five writing centre consultants were asked to complete a questionnaire comprising six open-ended questions, focusing mainly on the questions and questioning that occurs during the consultation:

- Question 1: How do you generally begin a consultation? What would be the three common questions you would ask to begin the discussion?

- Question 2: How do you respond when students are hesitant to ask questions or take the lead in the discussion or dialogue?

- Question 3: How important is it for students to respond to you or your questions? Why?

- Question 4: What impact, do you think, have your one-on-one sessions had on your tutees or students in the writing centre? Please provide examples to substantiate.

- Question 5: In your view, what makes for a successful consultation? 
- Question 6: Explain briefly if and how you think we apply the following principles in the writing centre: problem solving, critical thinking, student empowerment, social responsibility, student-centred focus, holistic education and an analysis of power.

Open-ended questions are used in surveys to provide respondents with the opportunity to freely express their opinions about issues (Infosurv Research, n.d.). They also allow greater insight into the views, opinions, and experiences of respondents than do closed-ended questions. It is for these reasons that the questionnaire administered to the writing centre consultants included six open-ended questions. Because such questions (in questionnaires especially) sometimes draw answers that are short and not detailed enough because of the time needed to respond effectively, the consultants were given close to a week to complete and submit these. This was done to also allow the consultant to reflect on the consultations before completing the questionnaire. The questions were structured to be interpretive. A response to an interpretive question is a subjective response that involves the thing that is being interpreted and the person doing the interpreting. An interpretive question has more than one answer, which that can be supported with evidence, in this case, from the actual consultation (Vocabulary.com, n.d.). The questions asked did not make specific reference to the aspect of social justice but, rather, asked questions related to the dialogue, discussion, and questioning that took place during the consultation. This was to ensure that the responses from the consultants were unbiased. It was important for the researcher to determine whether these principles of social justice did occur during the consultation without influencing the respondents in any way. All responses were then categorised according to the principles of social justice identified.

Brief quantitative evidence, from the evaluation forms students who visit the writing centre complete, are integrated into the discussion in the Findings and Discussions section as well. The evaluation forms or online surveys are e-mailed to students via the online booking tool once the consultation has ended. Completed forms are returned via e-mail. Statistics are automatically generated from the survey function of the online booking system. The survey comprises Likert-style questions, which give students 3 to 6 (e.g., yes, no, maybe; excellent, good, poor; excellent, fair, good, unacceptable, very good, average). The statistical analysis integrated into the discussion at the end of the paper is based on feedback between February and June 2017. Ethical clearance for the project has been granted by the faculty's Research and Ethics Committee. Consultants were required to fill out a letter of consent, which gave us permission to use their responses. They were also made aware of the fact that their anonymity was guaranteed and that they could withdraw from the research at any point

\section{Findings and Discussions}

The findings suggest that it is within the act of dialogue, in the context of the writing centre, that these social justice principles (problem solving, critical thinking, student empowerment, social responsibility, student-centred focus, holistic education and an analysis of power) are energised. The principles identified cannot be discussed as individual principles operating in isolation. In many instances, they operate simultaneously or in tandem. Sometimes they are very deliberate actions on the part of the consultant or the student-they happen implicitly, explicitly, directly, or indirectly. Take the social justice principles of problem solving and critical thinking, for example. No writing centre consultation begins with a request to focus on critical thinking or problem solving, yet a successful consultation cannot take place without actions and questions that require the student to solve a problem or think critically about a response, thought, view, issue, or choice. Baker (1988, p. 37) defined critical thinking as analysing arguments and reasoning thoughtfully and is in agreement with Glaser's definition (quoted in Baker, 1988) of critical thinking as involving a higher order of intellectual development, which includes the ability to reason. The act of effective academic writing cannot happen without problem solving and critical thinking. In the context of the writing centre consultation, it is through the 
act of asking and responding to questions that the student is encouraged, sometimes forcefully, to think critically. Consultant responses confirmed this:

I want them to respond because sometimes by asking questions and talking, they pick up their own mistakes, which is more valuable to them. It's good to sometimes act as facilitator for them to find their own mistakes, this way when they are editing their work at home they are more likely to pick up mistakes by themselves. (Consultant 1)

Being able to identify a mistake, understand why it is a mistake, and to apply the same rule, for example, to other writing to ensure the mistake is not repeated, is one small step towards problem solving. When asked to explain if and how the principles of problem solving and critical thinking are applied in the writing centre, responses confirmed the above:

\begin{abstract}
Asking students what they mean, how they could better phrase something, how they could go about answering a certain question or addressing a certain topic, requires them to solve their own "problems" and think critically about their own writing and the texts they are referring to. (Consultant 2)
\end{abstract}

To promote problem solving, consultants allow students to formulate their own ideas of which features should be included in an academic text before the consultant guides them. The student must therefore think for him/herself in order to solve their writing issues. This links to the concept of critical thinking as well, as the student must also evaluate his/her work in order to identify his/her writing issues. In both cases the consultant acts as a guide, empowering the student to become an independent thinker. (Consultant 4)

We look at each student's writing individually and encourage them to find their own errors so that the help they receive is sustainable and applicable to their future studies as well, and not just the individual assignment. (Consultant 1)

Hoon and White (n.d.) explained that, often, a number of ESL (English second language) students may be quiet or appear passive because they lack the metalanguage to ask questions or to talk about their writing, that the classroom atmosphere is too threatening and inhibiting for them to venture with their "assumingly stupid questions especially when the teacher is there to grade them" (p. 3). Talking to a peer, even a more knowledgeable, experienced peer is less daunting. More importantly, there is no fear of the end product-assessment. The student is encouraged to feel comfortable and safe without fear of reprisal. This view was confirmed in consultant responses to Questions 1 and 2 in the questionnaire (Question 1: "How do you generally begin a consultation? What would be the 3 common questions you would ask to begin the discussion?" Question 2: "How do you respond when students' are hesitant to ask questions or take the lead in the discussion or dialogue?"). Feedback indicates that consultants start the conversation by attempting to put the student at ease:

I generally start a first consultation by asking the student's preferred name and his/her study direction. I do this to establish a baseline for the direction the session is going to go, as well as putting the student at ease. (Consultant 3 )

Generally, I begin the consultation by confirming that the student is the one who booked with me ("Are you Mpho? Great! You're with me."). The next question I ask is, "What is your assignment on?" Frequently it is at this point that the students reach for their assignment topic, and while it is certainly useful to ensure that they understood it, I think it is important to hear the student's interpretation of the topic. (Consultant 2) 
I begin by asking the student which year he/she is and what subject they need help with. (Consultant 1)

With regards to Question 2, consultants indicated that when students were hesitant to take the lead they:

try to make them comfortable by giving a funny example and I make it clear that even though I am a senior student, I also struggle with writing sometimes. (Consultant 1)

Or,

beginning by asking the student about the assignment topic encourages them to take the lead. If they are hesitant, it is generally because they are worried that they are incorrect. I stress that I have not studied that subject, or it has been a long time since I studied it, and therefore I need them to explain certain aspects to me. This, I feel, is empowering to students as they take on the role of teacher/educator. Unless their draft is flawless, persistence in asking questions is key. (Consultant 2)

As can be seen here, even when a student is hesitant to participate, there are techniques used to draw the student into the discussion and to take the lead. Interestingly, even the tone and language choice make a deliberate effort to draw in the student and differ vastly from that of a formal lecture (Are you Mpho? Great! You're with me.).

Student feedback in response to the Comment and Suggestion category in the survey confirmed this:

Friendly consultant made me feel comfortable.

The consultant was brilliant, she could also speak my native language so I could easily relate... thank you.

She was patient with me and I felt very comfortable with her. I appreciate how she gave me advice I did not receive from the tutors in my faculty and she was very welcoming for me to [go] back for assistance with other subjects.

For those of us teaching academic writing, and attempting to be writers ourselves, we know that academic writing is a very personal experience. Each one of us brings to our writing our own personal problems, strongly influenced by a number of affective factors. While writing courses (as we do offer) introduce students to the principles and conventions of the different genres in their discipline, these courses are presented to an audience of writers of differing abilities, leaving very little time to focus on individual issues. It is only during these writing centre conversations, that students are awarded the opportunity to personalise the writing experience, tying in with the need to create a learning environment that is student-focused. Consultants confirmed this in the following responses to Question 4 ("What impact, do you think, have your one-on-one sessions had on your tutees or students in the writing centre?"):

The relative intimacy of the consultation creates a safe space for students to express their writing concerns without fear of ridicule. (Consultant 2)

They are more comfortable to share what they are struggling with due to the more open and interactive environment as opposed to the formal classroom set-up. (Consultant 5) 
I find that sometimes students become stressed and overworked and because of their stress about a particular essay, they cannot begin to write. One-on-one consultations give me the opportunity to give them perspective and calm them down. Many times they can write if they have the task broken down for them in manageable parts and they feel less overwhelmed. (Consultant 1)

This last response also indicates to us that, sometimes during the consultation, drawing in the contribution of the student requires that the discussion begin by not just focusing on writing but also other related issues that the student may be struggling with. The need to give perspective and calm them down probably suggests the need to determine what the student is stressed and pressured by, and perhaps give advice-not as a writing centre consultant, but as a senior student who has had similar feelings and experiences. Consultant 3 confirmed this in the following statement:

In my opinion and in my sessions, it has an impact on a personal as well as an academic level. Many of the first-year students were battling with adjusting to life at university and we could talk about that.

Talking about their writing allows students to talk aloud about their ideas, thoughts, and the arguments they want to put forward. Having a consultant to talk to about this means that these ideas and thoughts and arguments can take shape, and gaps that the tutor recognises can be filled by questions and discussions. In doing so, students are learning that writing, while a truly personal activity, is also an interactive one-that writing does not take place alone and in isolation, that talking with other people about your writing and, importantly, having other people look at your writing, can only serve to enhance the quality of the final text. In the course of this talking, too, one can see how issues of power come to the fore, as the student, normally silenced, finds a voice. This too was alluded to in consultant responses:

Once I had a student who had a long essay to write but she was so overwhelmed because she did not know how to approach the essay. So I helped her plan it and encouraged her as well. Afterwards she mentioned that she thinks all she needed was moral support to actually start writing. The one-on-one consultations provide moral support and personal writing help that a class situation cannot provide. (Consultant 1)

By getting students to ask questions, answer questions, and talk openly about their writing, we are focusing on their personal issue with writing, but we are also supporting them as they learn to solve problems independently. This is what Vygotsky probably referred to when he spoke about "supporting the learner's development and providing support structures to get to that next level" (cited in Raymond, 2000, p. 176). This is also moving closer to what the act of social justice would require. O'Sullivan and Cleary (2014, p. 56) called this

an inductive approach ... the peer-tutor encourages and helps the tutee to be involved in his/her own learning. . . . together they set up an agenda for the consultation that is purposeful and challenging, and together they work to achieve these goals.

This is in direct contrast to the banking approach to education that Freire was opposed to. It is also one which attempts to empower the student, giving him or her a voice and the freedom to control the direction of the consultation. Fraser's (2005) notion of social justice may not have to remain an ideal. This student-centred pedagogy and this student empowerment evident here is the first step towards ensuring that all participants participate as equals, as "full partners in social interaction" (Fraser, 2005, p. 73). The text that the student is working on is not the central point of the consultation-the student is. As North stated (1982), the text is essentially the medium-it is the writer we work on. Already, 
there is a shift from what commonly occurs at mass-education settings where the student is invisible. Elsewhere, I have written (Rambiritch, 2015, p. 16) that it is a student's writing that represents him or her. The students are invisible, and their written words are proof enough of their ability. The text to a student struggling alone with his or her writing can be the enemy-the barrier to academic success. In the writing centre the individual is central, the text secondary. Prioritising the student, being guided by what the student requires, and by asking questions rather than providing solutions means that the consultant can identify and provide additional support in areas that impact negatively on a student's writing-for example, reading, grammar, synthesising. The consultations, then, are aimed at developing the students holistically as opposed to focusing on writing as an isolated skill. Students are encouraged to come back as many times as they need to in the hope that we are given the opportunity to provide as much additional support as is necessary.

Dialogue, then, is key to what we do in the writing centre. Dialogue in English, mostly, in the hope of empowering our students. That alone is a contradiction. Dictated mainly by the institution's language policy, the medium of teaching, learning, and communication is now English, with support in Sepedi. In light of the fact that modules are offered only in English, support is provided in English. Feedback from consultants indicates that students who do speak another language still prefer the consultation to take place in English. However, Setswana, isizulu, or Afrikaans do become the default language when thoughts or ideas cannot be expressed in English. As one consultant stated, "They use an African language like Setswana to express ideas that they would otherwise struggle to express in English." The online booking programme purchased this year, which records personal information of students visiting the writing centre, indicates that $23 \%$ of students indicate English as their first or home language, $11 \%$ Afrikaans, and $16 \%$ did not indicate a first or home language, with the highest African language at $7 \%$ being isiZulu, and the lowest being isiNdebele and Tshivenda, both at $0.36 \%$. Interestingly, while Sepedi is a language of communication at this particular institution and indicated as such in the language policy, no student indicated Sepedi as a first or home language. While students do speak a range of South African languages, they prefer consultations to take place in English. How, then, does this truly reflect social justice? English is the language of oppression. Hooks (1994, p. 168) stated that it is the language of conquest and domination, "the mask which hides the loss of so many tongues, all those sounds of diverse native communities we will never hear." In South Africa too, language has always been and continues to be a contentious issue. How do we justify social justice while expecting students to read, write, and speak the very language that is most often the barrier to their academic success? I would like to think I can find an answer once again in hooks' words:

Learning English, learning to speak the alien tongue, was one way enslaved Africans began to reclaim their personal power within a context of domination. Possessing a shared language, black folks could find a way to make community. (1994, p. 170)

Using English as the medium of communication in the writing centre allows us the possibility of empowering our students to communicate in a language that may have, until now, silenced them. I refer to the students Hoon and White (n.d.) made reference to, and to many other ESL students who do not participate in classroom discussions because they do not see themselves as being adequately equipped with the necessary metalanguage. The academic institution can be a closed community, entry into which is often proficiency in English. Empowering students in English secures entry into this community. It also means that academic success, widening participation, and true access become possible. Hooks' (1994. p. 167) quoting of Adrienne Rich's poem, "The Burning of Paper Instead of Children," is relevant here: "This is the oppressor's language yet I need it to talk to you." The reality is that institutional requirements dictate that a student will be assessed on their ability to write-this too, in English. Encouraging dialogue in English could possibly instil in students a level of comfort with the language that they may not arrive here possessing. As comfort levels grow, so will confidence to 
use and write in the language. This may be one way of using the hegemonic language to give voice to our students - to ensure that they are neither marginalised nor silenced.

\section{Conclusion}

The narrative above suggests that the principles of social justice identified are applied successfully in the context of the writing centre. This is based on our understanding of these principles, as well as feedback from consultants. Evidence of student experiences in the writing centre has, in a few instances, been integrated into the discussion. More concrete evidence of the value of our support can be seen in students' responses to other questions as well. $94 \%$ of students agreed that "The writing centre is beneficial to me"; $96 \%$ agreed that "I felt confident to ask my consultant a question"; $94 \%$ agreed that "My consultant provided opportunities for me to ask questions." Students were very positive about the ability of the writing centre consultant to assist them with their writing, with $98 \%$ of students agreeing that the consultant was knowledgeable about academic writing and that they were provided with valuable advice on how to improve their writing. Most importantly, however, was students' response to the statement: "I will apply what I have learnt to other subject fields." For those of us working in the field of academic literacy, and academic writing specifically, we are well aware that the real value of what we do lies in our students' ability to apply what we teach them to the reading and writing they do throughout their academic careers - the transfer of skills is paramount in academic literacy and writing. Here $98 \%$ of students agreed.

This study set out to understand the concept of social justice as used in the higher education classroom, as well as to identify social justice principles that we could apply to the work that we do. Having identified these principles, the study showed that the principles, while not occurring in isolation, do occur during the dialogue that occurs between consultant and student. The real value of this study lies in the ability to do social justice, to empower students, give them a voice, develop them holistically, and contribute meaningfully to their learning as they find their way to academic success. Of course, this small-scale, mainly qualitative study is not the end of the road; it is, rather, just the very first step in evaluating the quality of such contributions to student development. Further, more intensive, quantitatively stronger evidence would be needed to measure the real success or effect of our support.

\section{References}

Aliakbari, M., \& Faraji, E. (2011). Basic principles of critical pedagogy. IPEDR, 17, 77-85.

Archer, A. (2011). Changing academic landscapes: Principles and practices of teaching writing at the University of Cape Town. In C. Thaiss, G. Bräuer, P. Carlino, L. Ganobcsik-Williams, \& A. Sinha (Eds.), Writing programs worldwide: Profiles of academic writing in many places (pp. 353-364). Fort Collins, USA: WAC Clearinghouse.

Archer, A., \& Parker, S. (2016). Transitional and transformational spaces: Mentoring young academics through writing centre. Education as Change, 20(1), 43-58.

Archer, A., \& Richards, R. (2011). Changing spaces: Writing centres and access to higher education. Stellenbosch, South Africa: Sun Press.

Ayers, W., Quinn, T., \& Stovall, D. (2009). Handbook of social justice in education. New York, USA: Routledge.

Baker, T. (1988). Critical thinking and the writing centre: Possibilities. Writing Center Journal, 8(2), 3741.

Brennan, J., \& Naidoo, R. (2008). Higher education and the achievement (and/or prevention) of equity and social justice. Higher Education, 56(3), 287-302. http://doi:10.1007/s10734-008-9127-3 
Brooks, J. (1991). Minimalist tutoring: Making the student do all the work. In R. Barnett \& J Blumner (Eds.), The Allyn and Bacon guide to writing center theory and practice ( $\mathrm{pp}$ 219-224). Boston, USA: Allyn \& Bacon.

Bruffee, K. A. (1984). Collaborative learning and the "conversation of mankind." College English, 46(7), 635-652.

David, M. (2010). Improving learning by widening participation in higher education. New York, USA: Routledge.

De Kadt, J. (2009) Education and Injustice in South Africa. Focus: A Journal of the Helen Suzman Foundation, 55, 26-30. Retrieved from https://hsf.org.za/publications/focus?b_start:int=24

Dover, A. G. (2013). Teaching for social justice: From conceptual frameworks to classroom practices. Multicultural Perspectives, 15(1), 3-11. http://doi:10.1080/15210960.2013.754285

Fouche, I. (2007). The influence of tutorials on the improvement of tertiary students' academic literacy. Per Linguam 23(1), 45-55.

Fraser, N. (2005). Reframing justice in a globalising world. New Left Review, 36, 69-88.

Freire, P. (1970). Pedagogy of the oppressed. London, UK: Penguin.

Giroux, A. (1997). Pedagogy and the politics of hope: Theory, culture and schooling, a critical reader. Boulder, USA: West View Press.

Gor, H. (2005). Critical pedagogies, pedagogy for human rights education. Paper presented at the International Symposium on Human Rights Education and Textbook Research, Kibbutzim College of Education, Israel.

Grant, M. K., \& Hoeber, D. R. (1978). Basic skills programs: Are they working? Washington, USA: American Association for Higher Education.

Hackman, H. W. (2005). Five essential components for social justice. Education, Equity \& Excellence, 38(2), 103-109. http://doi:10.1080/10665680590935034

Harris, M. (1986). Teaching one-to-one: The writing centre conference. Illinois, USA: National Council of Teachers of English.

Hooks, B. (1994). Teaching to transgress: Education as the practice of freedom. New York, USA: Routledge.

Hoon, T. B., \& White, C. (n.d.) Reforming ESL writing instruction in tertiary education: The writing centre approach. The English Teacher XXXV; 1-14.

Infosurv Research. (n.d.). How to code open-end survey question responses. Retrieved from http://www.infosurv.com/tag/coding/

Lewin, T., \& Mawoyo, M. (2014). Student access and success: Issues and interventions in South African universities. Cape Town, South Africa: Inyatelo.

Longfellow, E., May, S., Burke, L., \& Marks-Maran, D. (2008). They had a way of helping that actually helped: A case study of a peer-assisted learning scheme. Teaching in Higher Education 13(1), 93105.

Lotter, H. (1999). Rawls, Young and the scope of justice. Theoria: A Journal of Social and Political Theory, 94, 90-107.

Maxwell, M. (1990). Does tutoring help? A look at the literature. Review of Research in Developmental Education, 7(4), 2-8.

Mclnerney, P. (2004). Mapping the literature: Social justice and education. Adelaide, Australia: Flinders Unversity. 
Nelson, K., \& Creagh, T. (2013). A good practice guide: Safe-guarding student learning engagement. Queensland, Australia: Queensland University of Technology.

North, S. M. (1982). Training tutors to talk about writing. College Composition and Communication, 33(4), 434-441.

North, S. M. (1984). The idea of a writing centre. College English, 46(5), 433-446.

Novak, M. (2000). Defining social justice. First things. Retrieved from https://www.firstthings.com/article/2000/12/defining-social-justice

Olsen, G. A. (1984). Writing centers: Theory and administration. Urbana, USA: National Council of Teachers of English.

O'Neill, G., \& McMahon, T. (2005). Student-centreed learning: What does it mean for students and lecturers? In S. Moore \& B. McMullin (Eds.), Emerging issues in the practice of university learning and teaching (pp. 27-36). Dublin, Ireland: AISHE.

O'Sullivan, I., \& Cleary, L. (2014). Peer-tutoring in academic writing: The infectious nature of engagement. Journal of Academic Writing, 4(1): 52-65.

Patton, L. D., Shahjahan, R. A., \& Osei-Kofi, N. (2010). Introduction to the emergent approaches to diversity and social justice in higher education. Equity and Excellence in Education, 43(3), 265-278. http://doi:10.1080/10665684.2010.496692

Rambiritch, A. (2016). Student perceptions on writing support. Journal for Language Teaching, 49(2), 83-107.

Ramrathan, L. (2016). Beyond counting the numbers: Shifting higher education transformation into curriculum spaces. Transformation in Higher Education, 1(1), 1-9.

Rawls, J. (1971). A theory of justice. Cambridge, USA: Harvard University Press.

Raymond, E. (2000). Cognitive characteristics: Learners with mild disabilities. Needham Heights, USA: Pearson.

Shrestha, P. and Coffin, C. (2012). Dynamic assessment, tutor mediation and academic writing development. Assessing Writing, 17, 55-70.

Sleeter, C. E. (2014). Deepening social justice teaching. Journal of Language and Literacy Education. Retrieved from http://jolle.coe.uga.edu/wpcontent/uploads/2014/01/SSO Feb2015 Template.pdf

Thompson, I., \& Mackiewicz, J. (2014). Questioning in writing centre conferences. Writing Centre Journal, 33(2), 37-70.

Unit for Academic Literacy. (2007). Departmental self-evaluation. Pretoria, South Africa: University of Pretoria.

University of Pretoria. (n.d.). Unit for Academic Literacy. Retrieved from http://www.up.ac.za/en/unitfor-academic-literacy/article/23888/humanities-writing-centre

Vocabulary.com. (n.d.). Interpretive. Retrieved from: https://www.vocabulary.com/dictionary/interpretive 